\title{
AP-DICUMBA: APRENDER PELA PESQUISA A PARTIR DE ANIMAÇÓES PARTICIPATIVAS
}

\author{
Pedro Henrique Dangui Bellardo ${ }^{1}$ \\ Isis Lemes Vicente ${ }^{2}$ \\ Eduardo Bello Dunker ${ }^{3}$ \\ Everton Bedin ${ }^{4}$
}

Resumo: Este trabalho apresenta uma aproximação lúdica, atualmente teórica com modelo prático, da metodologia Dicumba (Desenvolvimento cognitivo universal-bilateral da aprendizagem), a APDicumba (Animação Participativa na Dicumba), onde o aluno possui a liberdade de definir tanto a animaçáo quanto o objeto de estudo dentro do universo escolhido para aprender química por meio da pesquisa. Na AP-Dicumba o professor possui o papel de orientador-facilitador, firmando raízes nas teorias de Carl Rogers e de Paulo Freire, que tornam imprescindível a pesquisa para que seja possível ensinar. Para tanto, realizou-se um levantamento bibliográfico e posterior triangulação de dados a partir de artigos relacionados a Dicumba, bem como a autores que interagem para a

1 Graduando em Licenciatura em Química e alunos de Iniciação à Docência vinculado ao Programa Institucional de Bolsa de Iniciação à Docência.

2 Graduanda em Licenciatura em Química e alunos de Iniciação à Docência vinculado ao Programa Institucional de Bolsa de Iniciação à Docência.

3 Graduando em Licenciatura em Química e alunos de Iniciação à Docência vinculado ao Programa Institucional de Bolsa de Iniciação à Docência.

4 Graduado em Química Licenciatura Plena pela Universidade de Passo Fundo - UPF (2009). Especialista em Tecnologia de Informação e Comunicação na Educação - TICEDU - pela Universidade Federal de Rio Grande - FURG (2014), Gestão Educacional pela Universidade Federal de Santa Maria - UFSM (2018) e em Educação Ambiental e Desenvolvimento Sustentável pela Faculdade Dom Alberto (2018). Mestre em Educação em Química pela Universidade Federal de Uberlândia - UFU (2012). Doutor em Educação em Ciências: química da vida e saúde pela Universidade Federal do Rio Grande do Sul - UFRGS (2015). PhD pela Universidade Federal do Rio Grande do Sul - UFRGS - no Programa de Pós-graduação: Educação em Ciências: química da vida e saúde, onde desenvolveu a metodologia DICUMBA - Desenvolvimento Cognitivo Universal-bilateral da Aprendizagem. Atualmente é professor permanente no Departamento de Química da Universidade Federal do Paraná (UFPR) e nos Programas de Pós-graduação em Educação em Ciências e em Matemática (PPGECM) e no Mestrado Profissional em Química em Rede Nacional (PROFQUI). Possui experiência na área de Química com ênfase em Química, trabalhando, principalmente, nos temas: formação docente, ensino-aprendizagem, TICs, interdisciplinaridade e metodologias de ensino. 
construção de uma base sólida à inserção da ludicidade na metodologia Dicumba. Ademais, a partir do estudo, demonstra-se por meio da animação "A Era do Gelo 2: o Degelo" uma forma prática e lúdica de desenvolver a AP-Dicumba por meio de 9 passos, dependendo, exclusivamente, da açáo conjunta e colaborativa entre professor e aluno.

Palavras-chave: Dicumba. Aprender pela Pesquisa. AP-Dicumba.

\title{
AP-DICUMBA: LEARNING THROUGH RESEARCH FROM ENGAGING ANIMATIONS
}

\begin{abstract}
This study presents a ludic approximation of the Dicumba methodology (UniversalBilateral Cognitive Development of Learning), the AP-Dicumba (Engaging Animation in Dicumba). The adapted methodology is currently theoretical, presenting a practical model, and it provides the student the freedom to define both the animation and the object of study within the cinematic universe chosen, aiming at learning chemistry through research. With AP-Dicumba, teachers have the role of advisors/facilitators, based on the theories of Carl Rogers and Paulo Freire, which establish research as an essential practice in teaching. To this end, a bibliographic survey and subsequent data triangulation were conducted based on articles related to Dicumba, as well as to authors who contributed in building a solid foundation for the inclusion of ludic elements in the Dicumba methodology. Furthermore, through the animation "Ice Age: The Meltdown", we propose a practical and playful way to use AP-Dicumba in 9 steps, depending, exclusively, on the mutual and collaborative work between teachers and students.
\end{abstract}

Keywords: Dicumba. Learning through Research. AP-Dicumba.

\section{INTRODUÇÃO}

Em diversos contextos são produzidos conhecimentos de diferentes culturas e de múltiplos desenhos voltados para o desenvolvimento significativo dos processos de ensino e aprendizagem. De maneira tangencial a proposição, encontra-se o docente como um meio potencializador dessa ação, o qual mune-se de competências e de habilidades relacionadas a metodologias de ensino para a qualificaçáo da formaçáo discente, tanto no sentido cognitivo quanto nos sentidos psicológico e científico. Nesse ângulo, compreende-se que as metodologias de ensino, quando usadas de forma didático-pedagógica, favorecem a formação do aluno, pois lhe possibilitam vivenciar e aprender o saber científico próximo a própria realidade.

Assim, entende-se que não é possível apenas apresentar o conteúdo e os conceitos científicos aos alunos; deve-se estimula-los e possibilitá-los vivenciar a aprendizagem a partir daquilo que lhes é curioso e interessante, a fim de, conscientemente, agregar valor social e científico a sua formaçáo. Logo, o presente artigo tem como objetivo apresentar uma proposta de atividade que aproxima os pressupostos da ludicidade à metodologia Dicumba (Desenvolvimento Cognitivo Universal-Bilateral da Aprendizagem), possibilitando uma mudança robusta entre o ensino tradicional e o ensino focado na pesquisa. Essa proposta denomina-se: 
AP-Dicumba (Animação Participativa ${ }^{5}$ no Desenvolvimento Cognitivo UniversalBilateral da Aprendizagem), que, além do Aprender pela Pesquisa Centrada no Aluno (APCA), propóe um aperfeiçoamento e uma reinvenção profissional à ação docente, trabalhando com referências culturais que demonstram traços da personalidade do aluno.

Afinal, acredita-se que compreender esses traços pode aprimorar e avigorar o trabalho do professor, uma vez que desenvolverá aulas mais diretivas e interessantes para os discentes. Destarte, entende-se que o lúdico, para além de ser uma forma de "promover uma alfabetização significativa na prática educacional, é incorporar o conhecimento através de características do conhecimento de mundo" (SALOMÃO, MARTINI E JORDÃO, 2007, p.5) e, portanto, a ludicidade não está nos eventos culturais, mas na interação do sujeito com a experiência (GOMES, 2004) que, vinculada a metodologias de ensino que favorecem o seu interesse e a sua curiosidade, proporcionam a esse uma formação mais integral.

A AP-Dicumba torna-se, portanto, uma ferramenta capaz de guiar a construção do conhecimento científico por parte do discente, com potencial para a construção de uma visão crítica por meio do professor-facilitador, com um caráter inicialmente simples e atrativo, graças à presença da ludicidade. Nesta esfera, entende-se que a aproximaçáo lúdica se torna uma possibilidade significativa à metodologia Dicumba, uma vez que o convívio com animaçóes é muito mais cotidiano nas açôes dos jovens desde a primeira infância. Isto é, utilizar a animação como um meio atrativo e agente de união à pesquisa pode aprimorar de forma relevante a metodologia Dicumba, além de tornar o conhecimento lúdico e conjunto de ser construído.

Neste enlace, o texto se divide em 3 seçôes distintas e complementares, sendo essas: i) Dicumba: uma metodologia de ensino via pesquisa, onde se traz detalhadamente uma forma de desenvolver a metodologia; ii) AP-Dicumba: a inserção do lúdico na metodologia Dicumba, apresentando-se os pressupostos da ludicidade à metodologia Dicumba; iii) Sugestão de aplicação da proposta pedagógica AP-Dicumba, em que se apresenta a aplicaçáo da AP-Dicumba.

\section{DICUMBA: UMA METODOLOGIA DE ENSINO VIA PESQUISA}

O ensino de química, atualmente, possui uma série de especificidades que dificultam o entendimento dos objetos de conhecimento dessa ciência, principalmente no que se refere à abordagem dos conteúdos que, de acordo com Bedin (2019), ainda são trabalhados de forma lógico-matemática e não em uma linha contextual de abordagem fenomenológica, tornando o ensino cansativo e tradicional. Como proposta ativa no sentido de minimizar o método tradicional

5 Animação Participativa é a animaçáo utilizada como um instrumento pedagogicamente atrativo e desencadeador de um dado conhecimento, possibilitando significativamente a uniáo de microconhecimentos do universo animado para a construçáo de macro-conhecimentos científico. 
de ensino, Bedin e Del Pino (2018a; 2019a) sugerem a metodologia Dicumba (Desenvolvimento Cognitivo Universal-Bilateral da Aprendizagem), a qual consiste na aprendizagem dos conceitos e dos conteúdos da ciência química por meio do APCA, em que a pesquisa deriva de um tema de interesse do aluno. Os passos sugeridos para a aplicaçáo e o desenvolvimento dessa metodologia podem ser observados na Figura 1.

Figura 1: Passos hipotéticos para o desenvolvimento da metodologia Dicumba.

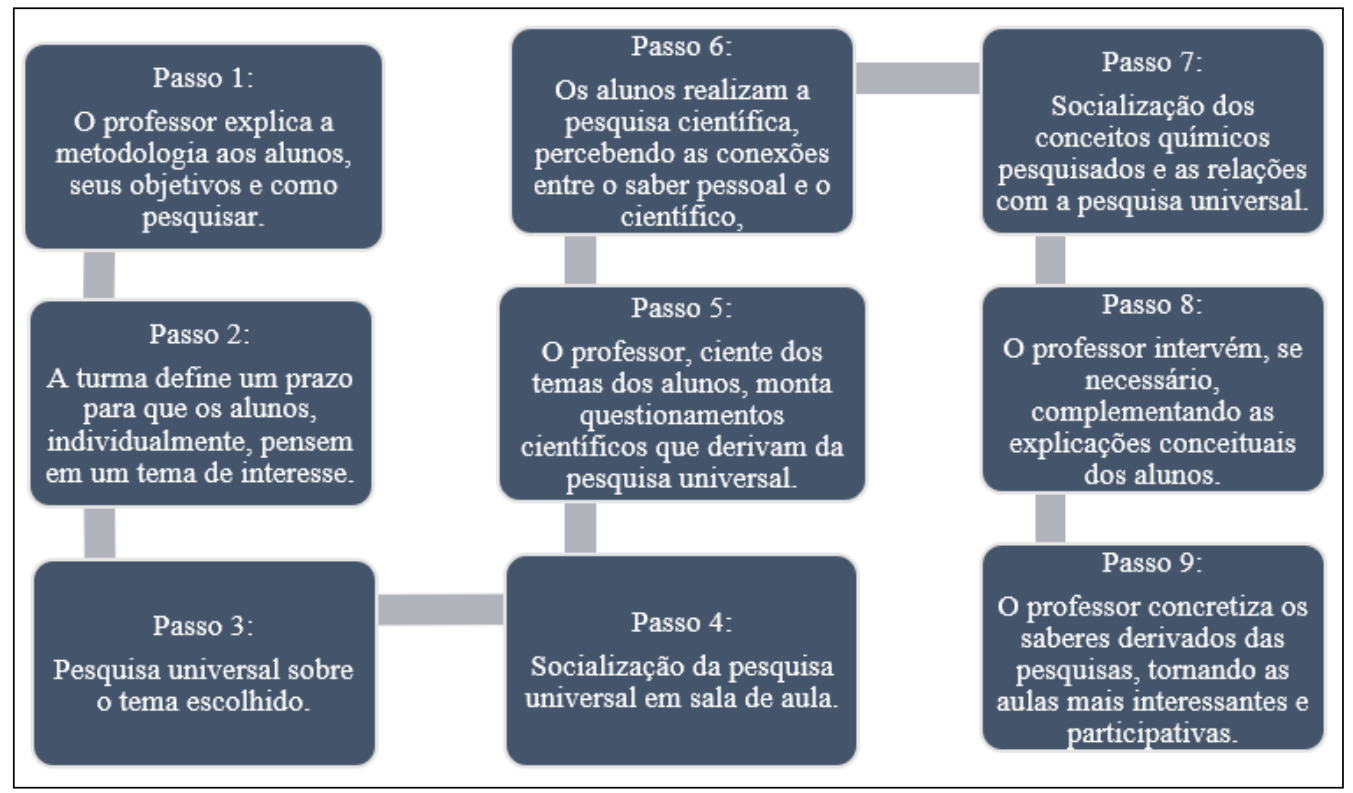

Fonte: Adaptado de Bedin e Del Pino (2019b).

Considerando o exposto na Figura 1, percebe-se que a metodologia exposta possui uma rota organizada, ainda que, na prática, torne-se bastante abrangente e única para cada um dos alunos, tornando a experiência dos discentes específica e o trabalho do professor menos monótono. Este desenho é importante porque, mesmo que alunos de uma mesma turma escolham um mesmo tema de interesse, além da percepção e da curiosidade sobre o mesmo tema ser diferente, o professor pode realizar conexôes científicas diversas, instigando os sujeitos a pesquisarem vieses dessemelhantes.

Os passos 1 e 2 fundamentam a introdução da metodologia aos alunos, uma vez que, além de ser de suma importância que cada sujeito esteja ciente do que fará, como irá fazer e porque fará, formalizar um acordo de responsabilidade dos alunos com o professor, onde os sujeitos possuem prazos para entregar o trabalho acordado, dentro do escopo de liberdade para determinar o assunto pesquisado, é de total importância para o desenvolvimento do mesmo. Dessa forma, a sala de aula, desde o primeiro momento, torna-se um ambiente mais democrático, onde as ideias podem ser debatidas dentro da realidade de cada aluno. 
Os passos 3 e 4 se unificam na ação de incluir o aluno em seu contexto, principalmente em dois aspectos; o primeiro, presente no passo 3, quando se possibilita ao aluno o estudo sobre algo que lhe é interessante e, possivelmente, importante, trazendo à tona um potencial que provavelmente não afloraria em temas pré-determinados que possuem relaçáo apenas com aquilo que o docente define como essencial. O segundo, presente no passo 4, situa-se na interaçáo do ambiente sala de aula, onde os alunos, ao socializarem as suas ideias, trocam gostos, opiniōes e conhecimentos, formando teias de informação e laços de pertencimento e acolhimento dentro do ambiente escolar. Este momento entre os sujeitos é importante porque "as Rodas de Conversa potencializam o diálogo entre os sujeitos em um viés de formação cooperativa, pois há valorização das concepçôes do outro e compreensão sobre as colocaçôes que se referem à história de vida de cada um (BEDIN; DEL PINO, 2019a, p. 21).

No passo 5, por sua vez, o professor usufrui de seus conhecimentos disciplinares e curriculares, a fim de relacionar os objetos de conhecimento da ciência química com os temas de interesse e de curiosidade dos alunos. Este passo é importante porque requer do professor habilidades e competências em reconhecer que precisa estudar mais para compreender o universo do aluno dentro da ciência química, e não o inverso. Trata-se de um momento em que o docente precisa pensar nos conceitos e nos conteúdos da ciência química a partir dos temas de interesse dos alunos, interligando-os na medida em que o sujeito expóe as suas ideias e as suas perspectivas socioculturais. Além do mais, é neste passo que o docente deve ser claro e específico, a fim de direcionar cientificamente o aluno, pois o sujeito irá realizar uma pesquisa, organizar ideias e, entấo, relacionar os elementos de interesse com os objetos de conhecimento da ciência química.

Nessa perspectiva, os passos 6 e 7, fortalecendo o destacado nos passos 3 e 4, possuem internamente o fator científico unido a pesquisa e a socializaçáo. É essencialmente nesses passos que o aluno compreende como a ciência química interage e se faz presente com/naquilo que lhe interessa, gerando empatia pelo estudo científico por meio do tema escolhido. Em síntese, percebe-se que é no passo 6 que o assunto definido pelo aluno no passo 2 se torna uma ponte para que o mesmo obtenha compreensão química, entendendo os objetos de conhecimento dessa ciência por meio da pesquisa centrada em seu interesse.

Neste enlace, compreende-se o papel da Dicumba no intuito de instigar o aluno à pesquisa, pois Freire (2009) afirma que os discentes priorizam a própria análise da evidência e buscam meios de explicá-la e, portanto, produzem ciência por meio de sua investigação. Não diferente, o passo 7 assume um papel não apenas de troca de interesses e de vivências, mas de conceitos e de conteúdos científicos, possibilitando um ambiente em que a química pode ser debatida por meio das especificidades científicas que cada um dos estudantes trouxe em sua pesquisa.

Mais precisamente, no cerne da metodologia, essa importância da pesquisa se mostra existente nos passos 5, 6, e 7. Ou seja, no passo 5 o professor faz as devidas relaçóes com a ciência química e, ao fazê-las, necessita pesquisar o tema de interesse 
do aluno, nutrindo o seu repertório cultural. No passo 6, a pesquisa científica realizada pelo aluno ocorre em um processo que une o interesse pessoal do sujeito com os conceitos específicos da ciência química, levando a um entendimento mais completo e aprofundado. No passo 7 , demonstra-se as capacidades de o aluno náo só absorver o conteúdo, mas da sua vivência e dos seus gostos pessoais, assumindo, assim, uma identidade cultural.

Para Freire (2019), garantir e se possibilitar assumir uma identidade social, histórica e humana em uma educação crítica é, indubitavelmente, de importância imensurável para o professor se enxergar em sala de aula. Logo, se ao professor já é de imensa importância, acredita-se que receber e gerar esses estímulos de identidade seja bilateralmente efetivo também para o discente. Afinal, este é um mecanismo de enxergar o aluno não só como um objeto de aprendizagem em sala de aula, mas como o centro de um processo de formação social, cultural e científica, extremamente necessário e benéfico à criticidade e ao interesse do sujeito, que se estabelecem as relaçôes interpessoais.

De outra forma, Bedin e Del Pino (2017, p. 156) afirmam que:

[...]na relação estabelecida com o saber, deve-se privilegiar as relaçóes sociais e o próprio ambiente em que o estudante se encontra, pois a aprendizagem ocorre a partir da troca de informaçóes e/ou experiências. Assim, para que o aluno se construa saberes, tendo como referencial social seus colegas e seu professor, agente mediador de transformaçóes entre ele, o objeto de estudo e o mundo ao qual pertence, é preciso estruturar, internalizar e contextualizar as informaçóes da sua vivência em forma de saber científico.

Ademais, no passo 8 percebe-se que o docente orienta os alunos na construção de conhecimentos, ressignificando os conceitos, caso haja alguma dúvida sobre as relaçóes entre o tema de interesse e os conteúdos científicos emergidos na pesquisa. Com isso, em conjunto com o passo 9, é realizada uma conversaçáo com os alunos para explorar as principais conclusões das pesquisas, bem como estabelecer elementos significativos do seu aprendizado. Ainda, é no passo 9 que o professor usufrui das pesquisas realizadas pelos alunos, em particular dos conceitos e dos conteúdos científicos emergidos, para desenvolver curricularmente alguns objetos de conhecimento da ciência química, criando aulas mais participativas, interativas e interessantes.

Diante do exposto, pode-se perceber que o professor tem o papel de potencializar e de promover um ambiente onde o discente constrói os seus próprios saberes de forma autônoma, recorrendo a ele caso o aluno encontre algum tipo de dificuldade. Ou seja, acerca da Dicumba, o professor atua como um veículo facilitador do processo de aprendizagem do aluno, enquanto que esse atua como edificador de seus conhecimentos a partir daquilo que lhe é importante, aprendendo náo somente sobre os temas de interesse, mas interiorizando-os a partir da pesquisa em sua aprendizagem. Este desenho é importante para o aluno tornar-se um sujeito ativo e autocéfalo, capaz de levar o ensino e a pesquisa para além dos muros da escola, sendo esses atuantes em sua vida e no meio em que interage. 
Além disso, a Dicumba exige que o professor reorganize o currículo a partir dos temas de pesquisa dos alunos, buscando desenvolver os conteúdos e os conceitos da ciência química por meio do interesse e do desejo do sujeito. Neste sentido, Bedin e Del Pino (2018b, p. 340) partem do pressuposto de que:

[...]a pesquisa realizada pelo aluno a partir de seu interesse e desejo por um tema, a fim de entender, em meio ao desenvolvimento de competências e habilidades à luz da prática pedagógica, um conteúdo científico é componente importante de seu desenvolvimento cognitivo. Tal pressuposto está ancorado numa concepção ampliada sobre a qualificação dos processos de ensinagem, tendo o aluno como autor da sua própria formação, aquela que não se encerra na Educação Básica, mas envolve um processo contínuo, que se estende ao longo de todo o desenvolvimento e maturação do pensamento, da reflexáo e da argumentação crítica construtiva.

Nesta perspectiva, a metodologia supracitada tem em uma de suas facetas a teoria de aprendizagem de Carl Rogers. Isso é importante porque como o sistema de educação atual náo corrobora ao desenvolvimento de um ensino eficaz, no sentido de o aluno sentir prazer e ter curiosidade, Rogers (1985) estabelece que o ato de ensinar é uma constituição individual e única para cada sujeito, de forma que a abordagem de ensino se torna algo centralizada no aluno (ACP - Abordagem Centrada na Pessoa). Nesta esfera, entende-se que o professor não é mais aquele que apenas compartilha os seus conhecimentos científicos, mas assume um papel de educador-facilitador que permeia pelos interesses individuais do aluno e o guia para a compreensão do saber; "a responsabilidade de tornar o curso interessante é problema individual” (ROGERS, 1973, p. 34).

O modelo rogeriano de ensino, ainda, propicia um ambiente democrático, onde o aluno, ao se tornar autor das próprias escolhas, e por consequência do próprio conhecimento, responsabiliza-se pelas decisóes que toma, tornando-se consciente de suas atitudes, desenvolvendo criticidade e reflexão sobre elas; a escola se transforma em um ambiente de formação cidadá. Neste sentido, Oliveira (2015, p. 40) afirma que:

O facilitador, por não considerar que os conhecimentos que possui são necessariamente os relevantes a serem transmitidos aos seus alunos, liberta-os para que realizem uma aprendizagem autodirigida. Logo, o importante não é o que se aprende, mas sim, aprender. $\mathrm{O}$ bom facilitador na educação é aquele que ensina o aluno a aprender. $\mathrm{O}$ aluno por sua vez, aprende a aprender.

O papel docente, portanto, na metodologia Dicumba é realojado. Em um primeiro momento, no modelo tradicional, o professor detinha os saberes e a aula era uma exposição dos conhecimentos científicos hierarquicamente organizados a partir da concepção docente, a qual foi metodicamente construída em um ambiente de educaçáo formativa. Por outro lado, na Dicumba, o importante na açáo docente é dar suporte e nortear o aluno na própria construçáo do saber a partir das pesquisas, bem como identificar veracidade de fontes, ensinar a aprender e a pensar. Para isso, acredita-se que seja de suma importância o uso da pesquisa em sala de aula, pois: 
Não há ensino sem pesquisa e pesquisa sem ensino. Esses quefazeres se encontram um no corpo do outro. Enquanto ensino continuo buscando, reprocurando. Ensino porque busco, porque indaguei, porque indago e me indago. Pesquiso para constatar, constatando, intervenho, intervindo educo e me educo. Pesquiso para conhecer o que ainda não conheço e comunicar ou anunciar a novidade. (FREIRE, 2019, p. 30)

Por isso, o professor, como orientador, deve pesquisar e manter-se constantemente atualizado para efetivamente auxiliar o aluno a também fazê-lo. De outra forma, o professor não pode ser apático às situaçóes problemas que podem aparecer; é fundamental uma mente aberta (manter-se atualizado socialmente é uma das formas de ser indulgente) para conseguir compreender as dificuldades individuais e guiar da melhor forma os estudos do aluno, caracterizando uma aprendizagem expressiva que interrelaciona os objetos de conhecimento da ciência química com a realidade do sujeito.

Ademais, essas mudanças se mostram necessárias para Tardif (2012), uma vez que entende que o papel da educação e da ação de educar se alteram historicamente, onde inicialmente era visto como uma arte, passando pela compreensão de uma ação técnica até as constatações mais atuais, de que educar é interação. Enxerga-se a importância da metodologia exposta, porque se entende que o APCA, que é um processo de aprender pela pesquisa construída sobre os gostos pessoais e humanos do sujeito, deve ser desenvolvido de forma significativa no ensino de química no tocante a possibilitar ao sujeito assumir o protagonismo do processo de aprender.

\section{METODOLOGIA DA PESQUISA}

A pesquisa aqui descrita refere-se a um estudo bibliográfico qualitativo de natureza formativa, tratando-se de uma açáo com o intuito de compreender efeitos organizacionais relativos a dados narrativos e estudos individuais sobre a metodologia Dicumba, a fim de apresentar uma aproximação lúdica sobre a mesma. Este processo emerge a partir da triangulação do levantamento de informaçôes teóricas e práticas sobre a aplicação e o desenvolvimento pedagógico da metodologia, adaptando, com substituição ou acréscimo, postos-chaves e gatilhos que passam a atuar como agentes da ludicidade.

De outra forma, uma prospecção de informaçóes para fins técnico-científicos de cunho pedagógico foi realizada sobre a metodologia Dicumba para que, após a compreensão sobre o seu funcionamento e sobre o seu potencial transformador, tanto social quanto educativo, se pudesse encontrar elementos para a inserção da ludicidade. A aproximaçáo surge, então, com o objetivo de tornar o ensino de química, inicialmente, descomplicado, trazendo uma forma científica para aguçar e desenvolver a criatividade e a curiosidade do aluno desde os primeiros momentos do ensino de Ciências da Natureza, inserindo-o em um mundo onde a pesquisa se faz presente e a aprendizagem autônoma é exercitada.

Assim, para a aproximação dos pressupostos lúdicos à Dicumba, realizou-se uma análise e uma interpretação sobre os elementos teóricos e práticos elencados 
na revisão bibliográfica sobre a metodologia original, onde cada um dos passos foi cuidadosamente estudado para que as etapas pudessem ser (re)formuladas sem perder a essência da Dicumba, o foco no aluno, a pesquisa presente e o professor como agente facilitador. Assim, emerge a metodologia AP-Dicumba com base nas teorias e nos pressupostos da Dicumba, tendo como um dos principais eixos a inserção do lúdico nas práticas pedagógicas.

Tal estudo é interessante por se desenhar a partir de uma revisão bibliográfica, pois esta possibilita um "potencializar intelectualmente com o conhecimento coletivo, para se ir além. É munir-se com condiçóes cognitivas melhores, a fim de: evitar a duplicação de pesquisas, ou quando for de interesse, reaproveitar e replicar pesquisas em diferentes escalas e contextos" (GALVÃO, 2010, p. 2). Além disso, a autora expõe que é uma forma de "observar possíveis falhas nos estudos realizados; conhecer os recursos necessários para a construção de um estudo com características específicas; desenvolver estudos que cubram lacunas na literatura trazendo real contribuição para a área de conhecimento", bem como "propor temas, problemas, hipóteses e metodologias inovadores de pesquisa; otimizar recursos disponíveis em prol da sociedade, do campo científico, das instituiçóes e dos governos que subsidiam a ciência" (GALVÃO, 2010, p. 2).

\section{AP-DICUMBA: A INSERÇÃO DO LÚDICO NA METODOLOGIA DICUMBA}

Considerando que a utilização de animaçóes em sala de aula é, dentre outras, uma saída para o ensino tradicional, pois ainda que os alunos não estejam "parados" no tempo, entende-se que "o surgimento de novas tecnologias, dentro de uma nova relação espaço-tempo traz suficientemente informações rápidas e novas, as quais, mesmo superficialmente, fazem com que os alunos almejem atualizaçôes e busquem essas informaçóes" (BEDIN, DEL PINO, 2019a, p. 7). De outra forma, os desenhos animados estão presentes nas fases iniciais da formação dos jovens; alguns consomem esse tipo de entretenimento mesmo ao alcançar a fase adulta, mudando quiçá as plataformas onde são consumidos.

Nesta tendência, a inserção do lúdico na metodologia Dicumba é importante porque o lúdico é, ao mesmo tempo, um instrumento pedagógico e uma estratégia de ensino capaz de trazer a linguagem do aluno, bem como a sua visão e a sua compreensão de mundo, junto ao desenvolvimento do ensino químico, interferindo mutuamente. Neste aporte, é essencial que na educação básica sejam promovidas práticas escolares e técnicas que criam um ambiente para o desdobramento de várias habilidades do indivíduo, possibilitando-lhe aprender a partir da interação, do pensamento e do diálogo.

O lúdico pode ser utilizado como promotor da aprendizagem nas práticas escolares, possibilitando a aproximação dos alunos ao conhecimento científico. Neste sentido, ele se se constitui em um importante recurso para o professor desenvolver a habilidade de resolução de problemas, favorecer a apropriação 
de conceitos, e a atender as características da adolescência (KNECHTEL; BRANCALHÃO, 2008, p. 2)

Diante do exposto, é compreensível que, de fato, o lúdico é um instrumento de grande importância às práticas docentes com tençôes a aprendizagem e ao desenvolvimento cognitivo discente, pois ele é considerado um veículo facilitador para que o aluno consiga compreender o conhecimento científico, formandose de forma engajada e autônoma (SALOMÃO; MARTINI; JORDÁO, 2007; SANTAELLA, 2012). Neste aporte, a mudança da Dicumba para AP-Dicumba pode ser demonstrada conforme Figura 2.

Figura 2: Passos da metodologia AP-Dicumba.

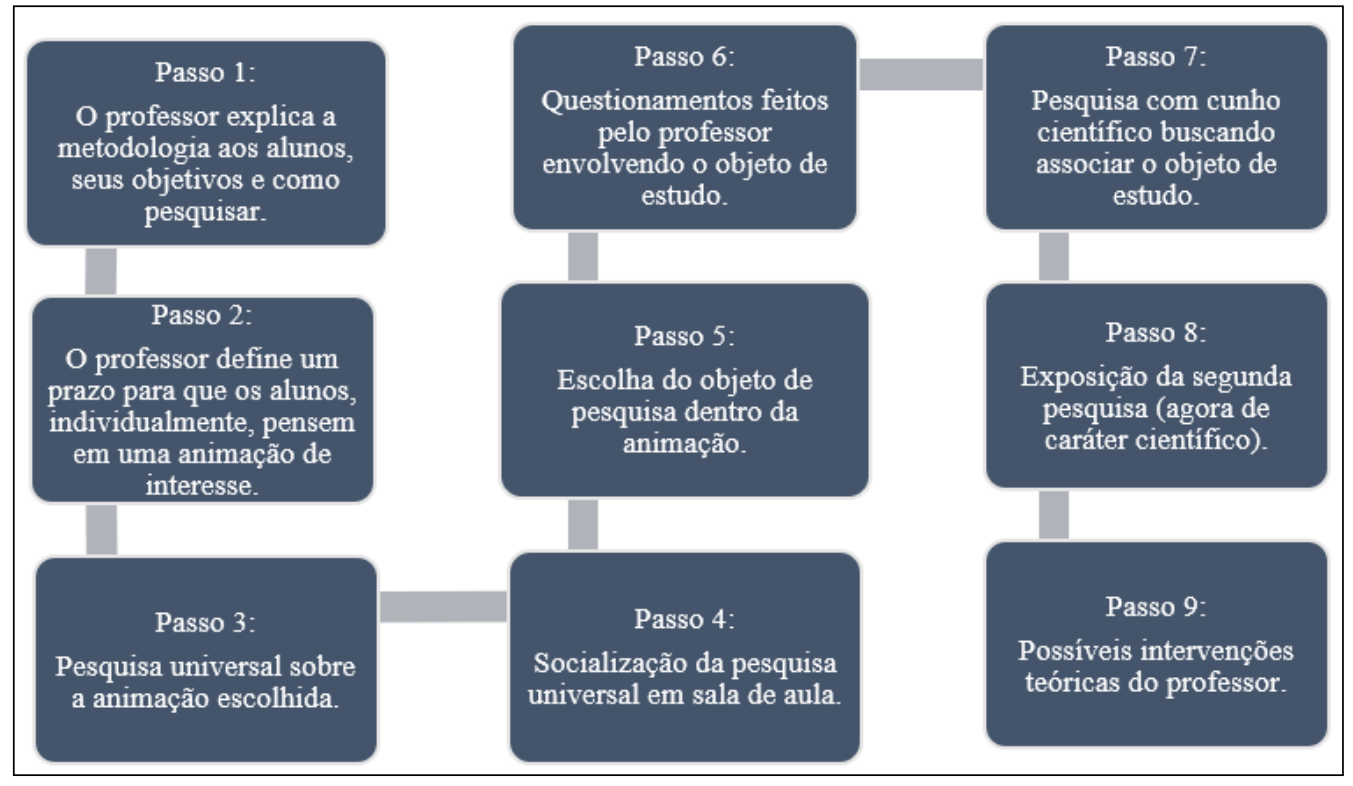

Fonte: autoria própria.

Ao observar a Figura 2, percebe-se que, assim como na metodologia original, o passo 1 da metodologia AP-Dicumba consiste na contextualização da atividade para a turma, explicando o passo a passo e instigando o interesse dos alunos para com a atividade, tal qual a compreensáo dos objetivos a serem alcançados ao final da aplicaçáo. Nesse caso, assegura-se o desenvolvimento de um ensino que pode propiciar de forma significativa "a aquisição de saberes expressivos na aprendizagem do aluno com vistas à sua formação plena" (BEDIN, DEL PINO, 2019a, p. 19). Neste campo, justifica-se a importância do passo 1 , uma vez que é necessário que o aluno compreenda como será realizada a atividade, para poder exercê-la de forma eficaz, alcançando o objetivo e desenvolvendo competências e habilidades, tais como: pesquisar, construir e compreender o conteúdo científico por meio de uma atividade lúdica e prazerosa (BEDIN; DEL PINO, 2020a). 
O passo 2 compreende a organizaçáo da metodologia, definindo prazos para que cada um dos estágios seja executado, bem como um momento de ceder espaço para o aluno pensar e escolher a animação de sua preferência. Os passos 3 e 4 objetivam, respectivamente, em uma pesquisa sobre a animaçáo, incluindo nela sua resenha e uma exposição, onde a turma junto ao professor determinam como ocorrerá. Por exemplo, se é preferível apresentaçóes curtas presenciais ou gravaçóes de vídeos com cerca de um minuto, publicados em alguma rede social ou site pré-determinado, expondo a resenha e as informaçóes importantes do universo animado selecionado. Assim como o passo 2, os dois últimos passos citados são muito semelhantes à metodologia que originou a AP-Dicumba, resumindo-se em uma pesquisa universal do tema (animação) e a sua socialização.

Em síntese, os passos 2, 3 e 4 constituem, juntos, a etapa de estudo focado na condensação de um micro-conhecimento, muito mais sociocultural do que científico, e que introduz a ludicidade à metodologia. Ou seja, é por meio desses três passos, em especial, que o professor tem um primeiro contato com os gostos e as preferências dos alunos em relaçáo a animação participativa, tornando-se uma oportunidade de criar vínculos com os discentes e construir um ensino mais apreciativo por eles. Desta forma, essas primeiras etapas tornam-se essenciais para uma aplicaçáo objetiva dos passos conseguintes que, apesar de não possuírem grandes mudanças da metodologia Dicumba, possibilitam ao estudante pensar para além de uma temática universal, bem como proporcionam o estudo específico sobre uma característica da animaçáo.

Neste sentido, ainda pode-se afirmar que na Dicumba quem define o viés específico de pesquisa é o professor, uma vez que o aluno traz uma temática de seu interesse, mas os direcionamentos científicos, que abraçam um caminho de afunilamento, são realizados pelo professor. Por exemplo, o aluno escolhe a temática futebol, o direcionamento docente pode estar diretamente enfatizado na câimbra (acidente no futebol), ou na bola e na grama sintética (material), ou no gasto calórico (exercício físico). A questão importante é que na adaptação AP-Dicumba, o direcionamento específico já é realizado pelo aluno, pois ele não apresentará um tema abrangente, mas a parte participativa deste, realizando pesquisas específicas sobre a mesma.

Os passos 2, 3 e 4 são importantes porque fomentam o interesse do aluno na pesquisa em si. São nos passos 3 e 4 que a animaçáo ganha importância, não do aluno que já possui interesse, mas do professor e da turma, que criam expectativas e desenvolvem ideias de conteúdos que podem ser trabalhados, mesmo que a decisão desse objeto de estudo seja única e exclusiva do aluno. Ainda, durante a discussão, dúvidas e opiniôes que emergem em um diálogo ajudam no surgimento e no amadurecimento dos objetos de estudo que seráo escolhidos no passo 5; essa conversa entre professor e aluno é importante porque, segundo Paulo Freire, ensinar exige segurança, competência profissional e rigorosidade para estimular a criticidade do aluno e a sua autonomia (CHIARELLA et al., 2015). Resumidamente, a ludicidade presente nesses passos é como a energia de ativaçáo necessária para que os passos seguintes ocorram de forma satisfatória, pouco mecânica e com ampla participação 
dos estudantes, pois, ainda que as pesquisas sejam individuais, as informaçóes são compartilhadas e o conhecimento é construído em equipe.

Definitivamente, trazer um objeto de estudo que de alguma forma apresenta uma bagagem emocional e se encontra relacionado à vivência do indivíduo é uma forma de instigar a curiosidade e a vontade do mesmo em estudar. Dito isso, a APDicumba apresenta como um dos seus objetivos principais a açáo de desenvolver uma relaçáo social forte entre o aluno e o professor-facilitador, sendo o lúdico a via que fomenta a criação da ponte entre as relaçôes, pois quando o aluno escolhe um tema de interesse, esse processo faz com que o professor compreenda melhor o aluno e a sua visão de mundo. Além disso, no passo 4, mais especificamente, o aluno mostra os seus saberes sobre a animaçáo escolhida, trazendo novos conhecimento para a turma e para o professor, formando uma rede de compartilhamento de conhecimentos, reforçando a ideia de Freire (2002, p. 25) de que "quem ensina aprende ao ensinar, e quem aprende ensina ao aprender", uma vez que a APDicumba realiza, de várias formas, a troca mútua de saberes.

Os passos 5 e 6 instituem juntos a transiçáo da primeira etapa, focada na reuniáo de micro-conhecimentos culturais, para a segunda etapa, focada na transformação e na construção dos micro-conhecimentos científicos, que são apreendidos de forma lúdica, uma vez que estáo intrinsecamente ligados a animaçáo e, portanto, a conhecimentos prévios de importância para o discente. Em especial, o passo 5, inédito na AP-Dicumba, consiste na determinaçáo de um objeto de estudo dentro da animação, sendo esse um evento, um personagem ou um objeto de fato. A determinação deste foco de pesquisa é essencial, uma vez que muitos autores, ao criarem suas animaçóes, criam universos extensos, sendo necessário uma seleção, por parte do aluno, de um único ponto pertencente a esse universo.

O passo 6 da AP-Dicumba é equivalente ao passo 5 da metodologia proposta por Bedin e Del Pino (2018a). Isto é, nesse passo o professor busca instigar a dúvida e a participação autônoma no aluno por meio de indagações de cunho científico sobre o objeto de estudo selecionado. É a partir dessa etapa que a ludicidade da metodologia se torna presente, pois, retomando Gomes (2004), a ludicidade está na interaçáo do sujeito com a experiência e não na simples existência do evento, nesse caso a animaçáo, e cabe ao professor, como facilitador para a pesquisa do aluno, elaborar os questionamentos sobre o objeto de estudo escolhido, promovendo o surgimento do lúdico e suscitando um terreno propenso para a germinaçáo de hipóteses, as quais serão confirmadas ou não por meio da pesquisa realizada; logo, cria-se um vínculo com o saber científico que, anteriormente, existia somente de forma implícita na animaçáo, como indica a Figura 3. 
Figura 3: Construção do Conhecimento na AP-Dicumba a partir do Lúdico.

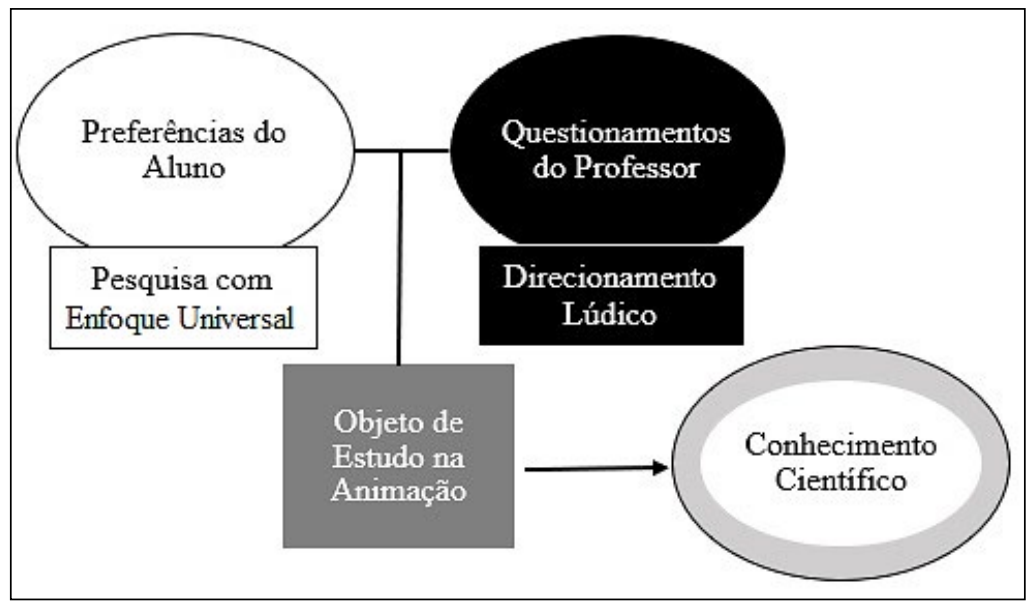

Fonte: autoria própria.

Os passos 7, 8 e 9, por fim, apresentam a etapa da constituição dos microconhecimentos científicos; é nesta etapa que reside a importância da animaçáo e do lúdico para essa adaptação. Os passos 7 e 8, especificamente, podem ser compreendidos como reproduçóes mais nichadas dos passos 3 e 4, mas, embora se resumam em pesquisa e exposição, desta vez o rigor científico se faz presente, tal qual a necessidade do exercício criativo por parte do discente. Afinal, ainda que o aluno compreenda a teoria em suas pesquisas, é fundamental que ele seja capaz de explicar como esta teoria se aplica ao objeto de estudo determinado. Isto é, mais do que simplesmente memorizar cálculos e regras que estabelecem as condiçóes para determinados eventos, o estudo por meio da AP-Dicumba se torna significativo para o aluno que passa a enxergar a ciência em eventos que não havia pensado que estaria; daí a importância de os alunos serem "envolvidos em tópicos científicos, colocando uma prioridade na evidência e na avaliação de explicações alternativas [...]. O uso de atividades de investigação pode ajudar os alunos a aprender ciência, a fazer ciência e sobre ciência” (FREIRE, 2009, p. 105).

Ademais, além de o processo conceder liberdade ao aluno para buscar e utilizar as fontes que justificam a sua hipótese, há, ainda, o imprescindível rigor científico, tornando o sujeito construtor dos próprios conhecimentos e autor da própria aprendizagem, capaz de identificar fenômenos, criar hipóteses sobre eles, investigar essas hipóteses e comunicá-las. Assim, entende-se que cada aluno tem a liberdade para aplicar as suas características únicas, as quais torna-o capaz de aprender e ensinar, sendo autêntico e apto em suas próprias singularidades. Ainda, entende-se que as habilidades desenvolvidas e as competências mobilizadas pelos alunos durante o movimento AP-Dicumba são extensíveis e necessárias a formação cidadã. 
Isto é, identificar e interpretar fenômenos, construir e organizar conhecimentos, criar e comunicar hipóteses são açóes essenciais para o desenvolvimento cognitivo e a formação do aluno, afinal, objetiva-se a internalizaçáo do saber científico na vida do sujeito, tornando-o ativo em seu meio e um cidadáo alfabetizado cientificamente. Além disso, tenciona-se a formação de um aluno autônomo, capaz de adquirir conhecimentos observando, teorizando, socializando, pesquisando e concluindo a própria realidade, entendendo o mundo em que vive como o local onde a ciência está presente e pode ser apreendida, independentemente de sua especificidade. Em síntese, anseia-se que, dentro da própria vivência e peculiaridade, o aluno seja capaz de aprender individualmente, construindo autenticamente suas teorias, comunicando-as e, enfim, as concluindo, com rigor científico e utilidade prática.

Nesta linha, tem-se que:

[...] as aprendizagens dependem das características singulares de cada um dos aprendizes; corresponde, em grande parte às experiências que cada um viveu desde o nascimento; a forma como se aprende e o ritmo da aprendizagem variam segundo as capacidades, motivaçóes e interesses de cada um dos meninos e meninas; enfim, a maneira e a forma como se produzem as aprendizagens são o resultado de processos que sempre são singulares e pessoais. (ZABALA, 2015, p. 34)

Assim, no aperfeiçoamento docente, acredita-se que a AP-Dicumba possibilita a desconstrução da hierarquia ainda hoje presente em sala de aula, criando aberturas para que o professor seja, assim como propõe Rogers (1986), autêntico, compreensível e sujeito que aceita e compreende os seus alunos como pessoas, enxergando o ensino do ponto de vista deles, praticando-o por meio da empatia. Estando em posse das características citadas, o professor é capaz de intervir construtivamente quando necessário na aprendizagem do aluno, utilizando animaçóes referências que sejam tanto de seu agrado quanto do discente, fomentando a emersão de um ambiente agradável, existindo interação, compartilhamento de informaçóes e de conhecimentos, bem como contribuição e colaboratividade para uma construção recíproca da compreensão da química em relação a criação de vínculos individuais e coletivos. Este processo, no entendimento de Freire (2019) e de Bedin e Del Pino (2019b; 2020b), proporciona um ensino bilateral, onde ao ensinar o professor aprende e o aluno, enquanto aprende, ensina o professor.

Entretanto, como destacam Lindonio, dos Santos e de Arruda Reis (2020, p. 5), para desenvolver uma prática que contempla a ação ativa do aluno, os professores, assim como a escola, precisam constantemente se atualizar e se aperfeiçoar, buscando sair da zona de conforto e do ambiente individualizado de ensino, necessitando "compreender que o ato de ensinar e aprender ultrapassa os muros da escola, envolve alunos, professores e comunidade". Afinal, como destacado por Bedin (2015, p. 41), "os processos de ensino e aprendizagem se conectam em uma unidade dialética entre a instrução e a educação; ensinar e aprender". Isto é, "entende-se que a relação entre os processos de ensinar e aprender tem uma estrutura e um funcionamento sistêmico, isto é, está composto por elementos estreitamente interrelacionados" (BEDIN, 2015, p. 41). 


\section{SUGESTÃO DE APLICAÇÃO DA PROPOSTA PEDAGÓGICA AP- DICUMBA}

Simulando uma possível aplicação da metodologia AP-Dicumba, foi selecionada a animação "A Era do Gelo 2: O Degelo", dirigida por Chris Wedge e co-dirigida por Carlos Saldanha, lançada nos Estados Unidos no ano de 2002. Neste sentido, o passo 1, como demonstrado na Figura 2, trata de uma açáo docente que enfatiza a contextualizaçáo à turma de como funcionarão as próximas atividades, bem como a metodologia AP-Dicumba. Na sequência, os passos 2 e 3 se resumem na determinação do tempo de escolha e na pesquisa sobre a animação. Nesse caso, a animação escolhida é "A Era do Gelo 2: O Degelo".

No passo 4, após o aluno realizar a pesquisa sobre o objeto do universo da animação, a mesma deve ser exposta de forma síncrona em sala de aula, ou assíncrona por meio da publicação de um vídeo curto em alguma plataforma escolhida pela turma junto ao professor. Este passo é importante porque nele devem conter informaçóes que expliquem o enredo da obra, assim como os personagens, o seu ano de estreia e mais algumas informaçóes vistas como relevantes, para que os alunos que não tiveram contato com a mesma possam entender e se inserirem no universo animado. Além disso, este passo é importante para o docente entender o que é interessante e curioso para o aluno, a fim de realizar os direcionamentos científicos; é relevante que o docente consiga realizar, durante a socialização da pesquisa pelo aluno, as direçóes científicas, ganhando tempo e enfatizando o contexto da pesquisa.

Representando a descrição do passo 4, tem-se: O filme "A Era do Gelo 2: O Degelo", estreado pela Fox Broadcasting Company e dirigido pelo estadunidense Chris Wedge e co-dirigido pelo brasileiro Carlos Saldanha, é a continuaçáo do filme "A Era do Gelo", onde se conta a história de Manny, um mamute, de Sid, uma preguiça, e de Diego, um tigre. No filme "A Era do Gelo 2: o degelo", há a inserção de novos personagens para dar continuação a trama, como Ellie, um mamute fêmea que acredita ser um gambá e seus irmáos adotivos, Eddie e Crash, que de fato são gambás. A obra se passa no período de tempo próximo ao fim da era glacial, com o aquecimento global e o derretimento das geleiras. A trama se constrói na fuga dos personagens para um possível barco que salvará todos aqueles que vivem no vale, esse que se encontra cercado por montanhas de gelo espesso por todos os lados e será inundado em pouco tempo com o rompimento de uma represa. Com o decorrer da história, os protagonistas notam que além da luta contra o tempo para náo serem alcançados pelo dilúvio iminente, eles precisam lutar contra o derretimento do próprio vale. $\mathrm{O}$ final do filme conta com os protagonistas enfrentando os seus maiores medos e uma reviravolta cômica, quando Scrat, um esquilo-dente-de-sabre e alívio cômico, cria uma grande fenda ao escalar um dos paredóes de gelo que circulam o vale. A fenda aumenta rapidamente de tamanho e abre espaço para que toda a água, que afogaria todos os animais, escorresse para fora, salvando a todos.

A exposiçáo do filme, o passo 5 corresponde à escolha pelo aluno de um objeto de estudo dentro da animação. Neste sentido, o objeto escolhido foi: "o 
derretimento do gelo". Isto é, o aluno possui algum vínculo ou interesse pelo tema e determinou que dentre todos os objetos, fenômenos e personagens envolvidos no filme, o derretimento do gelo é o que lhe desperta interesse e curiosidade; logo, cabe ao professor aceitar o tema do sujeito e desenvolver o passo 6. É importante destacar que o professor não possui a liberdade de alterar o tema escolhido pelo aluno, nem cogitar a hipótese de direcioná-lo para outro tema, uma vez que a metodologia frisa o APCA. Daí a importância de o professor, caso não tenha compreendido a socialização do aluno, ou deter informações básicas sobre a temática, buscar atualizar-se sobre o objeto de estudo do sujeito, a fim de concentrar esforços de direcionar cientificamente perguntas nesta vertente.

O passo 6 se constrói com a ação mais ativa do professor, responsável pela união do lúdico e do científico para que a associação ocorra na estrutura cognitiva do discente, quando comparado aos passos anteriores; é nesse passo que o docente, após aceitar e compreender o objeto de estudo do aluno, pesquisa sobre o mesmo e formula perguntas para mediar um estudo quanto a pesquisa com aporte científico, o qual será construído no passo 7. Nesse exemplo, retoma-se o objeto de estudo selecionado: "o derretimento do gelo", para a realização de duas perguntas, dentre uma infinidade de tantas outras que o docente pode realizar. A primeira delas é: "Cientificamente, por que o gelo derrete?"; e a segunda: "O aquecimento global é natural? Justifique.". Ao analisar as questóes, é possível perceber que em ambas, embora a presença da ciência esteja bastante evidenciada, a associação ao filme e, portanto, ao gosto pessoal do aluno é amplamente presente, tornando a relação entre as particularidades do sujeito, a sua experiência e a ciência claramente vinculadas.

É importante frisar que as perguntas, assim como a quantidade delas, são realizadas conforme o discernimento do professor sobre o objeto de estudo do aluno, uma vez que apenas uma única pergunta pode abranger um tema grande o suficiente para uma pesquisa completa, ampliando o acervo de saberes científicos e críticos do aluno. Além disso, é importante o docente ter clareza das perguntas que irá realizar, pois é necessário que o aluno compreenda da melhor forma como é possível relacionar o seu tema de escolha com o conteúdo de química que será abordado nas pesquisas. Diante disso, é de extrema precisão que o professor realize uma retomada de alguns conceitos científicos que possivelmente serão abordados devido as questóes e, em caso de algum discente ter alguma dúvida, que o docente possa explicá-los da melhor forma para a pesquisa ser bem guiada.

Tendo em vista essa dificuldade, é imprescindível que o docente se mantenha constantemente atualizado, para que seja capaz de responder e corrigir as questóes feitas pelos discentes, ou seja, o papel do professor náo é imóvel no tempo; o professor deve ser capaz de atualizar os próprios saberes práticos, tecnológicos e culturais para que seja capaz de desenvolver e construir com o aluno o conhecimento que o mesmo deseja obter, de forma clara, objetiva e interativa, sempre instigando o sujeito a procure mais sobre o tema, para que consiga desenvolver e internalizar o hábito de pesquisar e de desenvolver a sua independência intelectual. 
Os passos 7 e 8 prosseguem na tentativa de o aluno interpretar, pesquisar, relacionar e responder as questóes propostas pelo professor. Estes passos são importantes porque as respostas não estão prontas na Internet, devendo o sujeito entendê-las numa visão geral para relacioná-las; passo que possibilita interligar o objeto de estudo preferido e as indagaçóes docentes de cunho científico. No caso das perguntas realizadas, é provável que estas guiem o estudante para alguns conteúdos básicos da ciência química, como aqueles abordados em termoquímica e em química ambiental, por exemplo. Espera-se que ao responder a primeira pergunta o aluno introduza os conceitos de termoquímica, compreendendo o que é energia térmica, entalpia, reaçóes exotérmicas e endotérmicas, para compreender que o gelo funde graças a uma reação endotérmica, na qual, ao absorver energia do ambiente (vizinhança), as moléculas de água $\left(\mathrm{H}_{2} \mathrm{O}\right)$ se distanciam (fusão) devido ao aumento da energia cinética.

$\mathrm{Na}$ segunda pergunta, espera-se que o aluno se depare com questóes científicas abrangentes, as quais afetam a sociedade e afligem o meio ambiente. Será perceptível para o discente que o aquecimento global está relacionado ao efeito estufa, à camada de ozônio e à composição da atmosfera. Tendo isso em vista, a pesquisa irá guiar o aluno às consequências do aumento do aquecimento global e que, de fato, não é um "fenômeno natural" táo quanto o efeito estufa. Os gases estufa, como o dióxido de carbono $\left(\mathrm{CO}_{2}\right)$ e o metano $\left(\mathrm{CH}_{4}\right)$, são disseminados em maior abundância para a atmosfera devido as indústrias e os meios de transporte, bem como pela queima de combustíveis fósseis. A concentração desses gases na atmosfera faz com que o planeta fique mais aquecido, e os mantos de gelo fundam, levando ao aumento dos oceanos, secas, dentre outras atrocidades ambientais.

Ao fim da pesquisa, anseia-se que o estudante seja capaz de entender e de relacionar as respostas para construir a segunda exposição. Neste caso, é interessante pensar que o aluno, ao compreender cientificamente as reaçóes endotérmicas e o aumento de temperatura do planeta, correlacione os temas, pensando que o aumento da temperatura, gerado pelo efeito estufa, causa um acréscimo de energia térmica no sistema (planeta), que transfere às geleiras, uma vez que a energia térmica sempre se move do corpo mais quente para o corpo mais frio, acelerando o processo de fusão das calotas polares, problema muito discutido.

O passo 9 surge como um meio de o docente significar e ressignificar as informaçóes trazidas pelos alunos, pois é neste momento que o professor intervém, esclarecendo-as ou as complementando. Além disso, o docente também pode criar novas discussóes, corroborando à construção de argumentos e de pensamentos críticos e conclusivos sobre os assuntos. Por exemplo, o aluno que apresentou as suas pesquisas em relação a animação "A Era do Gelo 2: O Degelo" provavelmente focaria o conteúdo de termoquímica em reaçóes endotérmicas; o professor poderia exemplificar este conceito em outros fenômenos do contexto do aluno, ou complementar explicando sobre as reaçôes exotérmicas, bem como a relação explicita entre elas e dar ênfase as questóes energéticas. 


\section{CONCLUSÁO}

Ao término do texto, espera-se com a aplicação da metodologia AP-Dicumba, do ponto de vista discente, que o aluno náo seja apenas capaz de compreender a química como ciência fenomenológica, tanto a sua teoria quanto a sua aplicação, mas que a ludicidade, responsável por toda a adaptação em torno da metodologia Dicumba, fortaleça a criatividade do estudante, lhe dando liberdade para imaginar e teorizar sobre os diferentes eventos dentro do universo que lhe interessa e atrai, sendo capaz de interiorizar o método científico, bem como levá-lo para o seu cotidiano, tornando-se um agente de transformaçáo direto do meio onde vive e atua. De forma geral, entende-se que a ação docente não pode deixar a criatividade dos alunos desaparecer ou não aflorar, mas deve exercitá-la e fortalecê-la para formar cidadãos capazes de construir e de atingir os próprios objetivos, bem como serem capazes de compreender os obstáculos que residem em seu trajeto.

Ademais, da ótica docente, almeja-se que a metodologia AP-Dicumba atue como um motor para uma forma diferente de olhar a sala de aula e, sobretudo, a própria ação pedagógica, os processos de ensino e aprendizagem e os alunos. Assim, espera-se que a utilização desta metodologia possa modificar a prática docente diária em sala de aula, pois com ela o educador entende o educando náo como alguém incompleto, e que necessita ser preenchido com os conhecimentos científicos organizados de forma hierárquica, mas como alguém que possui a sua própria carga de saberes contextuais, práticos e fenomenológicos, necessitando organizá-los e significá-los. Afinal, muitas vezes, essa bagagem específica do aluno é esquecida pelo professor, fazendo-o perder a própria identidade.

Todavia, a proposta AP-Dicumba carece da bagagem do estudante, bem como do seu interesse e da sua curiosidade; o docente que atuar por meio desta metodologia estará aperfeiçoando-se diariamente como profissional ético e íntegro. Por fim, anseia-se que essa metodologia não somente seja aplicada para que o ensino, esquecido no tempo, torne-se algo interessante e satisfatório para alunos e para os professores, mas que sirva de inspiração para novas adaptaçóes, as quais atendam as especificidades e as particularidades das diferentes realidades, sempre levando em consideração as capacidades, os interesses e a imaginação dos estudantes.

\section{AGRADECIMENTOS}

Os autores agradecem as agências de fomento à pesquisa: Conselho Nacional de Desenvolvimento Científico e Tecnológico (CNPq) e Coordenação de Aperfeiçoamento de Pessoal de Nível Superior (CAPES), esta última via Programa Institucional de Bolsas de Iniciação à Docência (PIBID).

\section{REFERÊNCIAS}

BEDIN, E. A emersão da interdisciplinaridade no ensino médio politécnico: relaçóes que se estabelecem de forma colaborativa na qualificaçáo dos processos de ensino e aprendizagem à luz das tecnologias de informação e comunicação. Tese (Doutorado) 
Universidade Federal do Rio Grande do Sul. Instituto de Ciências Básicas da Saúde. Programa de Pós-Graduação em Educação em Ciências: Química da Vida e Saúde. Disponível em: <https://www.lume.ufrgs.br/handle/10183/126836>. Acessado em: 03 jan. 2021.

BEDIN, E. Filme, experiência e tecnologia no ensino de ciências química: uma sequência didática. Revista de Educação, Ciências e Matemática, v. 9, n. 1, 2019. Disponível em: $<$ http://publicacoes.unigranrio.edu.br/index.php/recm/article/view/4280>. Acesso em: 13 jan. 2021.

BEDIN, E.; DEL PINO, J. C. Concepções de professores sobre situação de estudo: rodas de conversa como práticas formadoras. Interfaces da Educ., Paranaíba, v. 8, n. 22, p.154185, 2017. Disponível em: <https://periodicosonline.uems.br/index.php/interfaces/ article/view/1600>. Acesso em: 24 fev. 2021.

BEDIN, E.; DEL PINO, J. C. A metodologia Dicumba como uma tempestade de possibilidades para o desenvolvimento do ensino de Química. Revista Brasileira De Ensino De Ciências E Matemática, v. 1, n. 1, 2018. Disponível em: <https://doi. org/10.5335/rbecm.v1i1.8479> Acesso em: 13 jan. 2021.

BEDIN, E.; DEL PINO, J. C. Dicumba-o aprender pela pesquisa em sala de aula: os saberes científicos de química no contexto sociocultural do aluno. Góndola, Enseñanza y Aprendizaje de las Ciencias: Góndola, Ens Aprend Cienc, v. 13, n. 2, p. 338-352, 2018b. Disponível em: <https://dialnet.unirioja.es/servlet/articulo? codigo=6750774> Acesso em: 13 jan. 2021.

BEDIN, E; DEL PINO, J. C. DICUMBA: uma proposta metodológica de ensino a partir da pesquisa em sala de aula. Ensaio Pesquisa em Educaçáo em Ciências (Belo Horizonte), v. 21, 2019a. Disponível em: <https://www.scielo.br/scielo.php?pid=S1983$21172019000100307 \&$ script=sci_arttext\&tlng=pt $>$ Acesso em: 13 jan. 2021

BEDIN, E; DEL PINO, J. C. Das Incertezas às Certezas da Pesquisa não Arbitrária em Sala De Aula Via Metodologia Dicumba. Currículo sem Fronteiras, v. 19, n. 3, p. 1358-1378, 2019b. Disponível em: <http://dx.doi.org/10.35786/1645-1384.v19.n3.32>. Acesso em: 13 jan. 2021.

BEDIN, E; DEL PINO, J. C. La movilización de competencias y el desarrollo cognitivo universal-bilateral del aprendizaje en la enseñanza de las ciencias. Paradigma, (Edición Cuadragésimo Aniversario: 1980-2020) (XLI), 360-383, 2020a. Disponível em: <https:// doi.org/10.37618/PARADIGMA.1011-2251.0.p360-383.id804>. Acesso em: 15 fev. 2021.

BEDIN, E.; DEL PINO, J. C. A metodologia Dicumba e o Aprender pela Pesquisa Centrada no Aluno no Ensino de Química: narrativas discentes na Educação Básica. Revista Insignare Scientia-RIS, v. 3, n. 3, p. 3-24, 2020b. Disponível em: <https://doi. org/10.36661/2595-4520.2020v3i3.11774>. Acesso em: 20 fev. 2021. 
CHIARELLA, Tatiana et al. A pedagogia de Paulo Freire e o processo ensinoaprendizagem na educação médica. Revista brasileira de educação médica, $v$. 39, n. 3, p. 418-425, 2015. Disponível em: <http://dx.doi.org/10.1590/198152712015v39n3e02062014>. Acesso em: 04 mai. 2021.

FREIRE, P. Em busca de sentido: um psicólogo no campo de concentração. 16 ed. Petrópolis/São Leopoldo, Vozes/Sinodal, 2002.

FREIRE, A. M. Reformas curriculares em ciências e o ensino por investigação. Actas do XIII Encontro Nacional de Educação em Ciências, Castelo Branco, 2009

FREIRE, P. Pedagogia da Autonomia: saberes necessários à prática educativa. Rio de Janeiro/São Paulo: Paz e Terra, 2019.

GALVÃO, Maria Cristiane Barbosa. O levantamento bibliográfico e a pesquisa científica. Fundamentos de epidemiologia. 2ed. A, v. 398, p. 1-377, 2010.

GOMES, C. L. Dicionário crítico do lazer. Auténtica Editora, 2004.

KNECHTEL, Carla Milene; BRANCALHÃO, Rose Meire Costa. Estratégias lúdicas no ensino de ciências. Secretaria de Estado de educaçáo do Paraná, v. 16, 2008. Disponível em: <http://www.diaadiaeducacao.pr.gov.br/portals/pde/arquivos/2354-8.pdf > Acesso em: 24 fev. 2021.

LIDOINO, A. C. P.; DOS SANTOS, D. D.; DE ARRUDA REIS, G. Reflexões sobre a formação continuada de professores na contemporaneidade. Research, Society and Development, v. 9, n. 9, 2020. Disponível em: <https://rsdjournal.org/index.php/rsd/ article/view/6473> Acesso em: 16 jan. 2021

MORAN, J. M. Desafios da televisão e do vídeo à escola. Integração das Tecnologias na Educação, p. 96-100, 2005. Disponível em: <http://penta3.ufrgs.br/MEC-CicloAvan/ integracao_midias/modulos/1_introdutorio/pdf/Desafios_da_TV.pdf> Acesso em: 18 jan. 2021.

MOZETO, A. Química atmosférica: a química sobre nossas cabeças.2001. Disponível em: <https://ria.ufrn.br/jspui/handle/123456789/1384> Acesso em: 20 jan. 2021.

OLIVEIRA, I. A. D. et al. Carl Rogers na educação de ensino médio. 2015. Disponível em: <http://tede.mackenzie.br/jspui/handle/tede/2876> Acesso em: 22 jan. 2021.

ROGERS, C. R. Liberdade para aprender. 1978.

ROGERS, C. Liberdade de aprender em nossa década. Artes Médicas, 1986.

SALOMÃO, Hérica Aparecida Souza; MARTINI, Marilaine; JORDÃO, Ana Paula Martinez. A importância do lúdico na educação infantil: enfocando a brincadeira e as situaçóes de ensino não direcionado. Portal de psicologia, 2007. Disponível em: <https:// bit.ly/3o01vPl>. Acesso em: 05 mai. 2021. 
SANTAELLA, L. O papel do lúdico na aprendizagem. Revista Teias, v. 13, n. 30, p. 11, 2012. Disponível em: <https://bit.ly/3eWSSkC>. Acessado em: 05 mai. 2021.

ZABALA, A. A prática educativa: como ensinar. Penso Editora, 2015. 